\title{
Percutaneous Balloon Valvuloplasty with a Modified Inoue Balloon for Stenosis of a Porcine Bioprosthesis in the Tricuspid Valve Position
}

\author{
George Kolke, M.D., Akira YAMADA, M.D., \\ Tetsuji Inou, M.D., Yoshitoshi Urabe, M.D., \\ and Akira TAKeShITA, M.D.
}

\section{SUMMaRY}

A 29-year-old woman with a stenosed prosthetic Hancock valve implanted in the tricuspid position underwent successful dilatation of the prosthesis by percutaneous transluminal balloon valvuloplasty using an Inoue balloon specifically modified for this valve. (Jpn Heart J 35: 809-812, 1994)

Key words: Tricuspid stenosis Hancock valve Percutaneous transluminal balloon valvuloplasty Modified Inouc balloon

4 OLLOWING an initial case report by Kan et al in 1982, ${ }^{1 /}$ percutaneous 1 transluminal balloon valvuloplasty has been a commonly used procedure for prosthetic as well as native valvular stenosis. However, there is only one report of a balloon valvuloplasty to a bioprosthetic tricuspid valve; in this case a Meditech balloon catheter was used (Feit et al in 1986). ${ }^{2)}$ We report a case in which balloon valvuloplasty with an Inoue balloon catheter (Toray) specially modified to suit a Hancock valve was performed for stenosis of a bioprosthesis implanted in the tricuspid position.

\section{Case Report}

A 29-year-old housewife had developed tricuspid stenosis and regurgitation probably subsequent to an episode of rheumatic fever or infective endocarditis at age 6. When she was 13 years old, a bioprosthetic valve (No. 27 Hancock) was implanted in the tricuspid position. She had been asymptomatic since the tricuspid valve was replaced. For 4 months prior to admission, she was in atrial flutter and New York Heart Association functional class I to II without digitalis or other

From Research Institute of Angiocardiology and Cardiovascular Clinic, Kyushu University School of Medicine, Fukuoka, Japan.

Address for correspondence: Yoshitoshi Urabe, M.D., Research Institute of Angiocardiology and Cardiovascular Clinic, Kyushu University School of Medicine, 3-1-1 Maidashi, Higashi-ku, Fukuoka-shi 812, Japan.

Received for publication March 22, 1994.

Accepted September 28, 1994. 
antiarrhythmic drugs. As she was contemplating pregnancy, she was admitted to our department for evaluation of function of the bioprosthetic valve. On physical examination, there was a tricuspid opening snap and a grade II/VI diastolic rumble at the lower left sternal border. The electrocardiogram showed atrial flutter on admission, which converted to sinus rhythm following electrical cardioversion. The echocardiogram and Doppler study showed an enlarged right atrium and moderate stenosis of the prosthetic valve (valve area: $0.5 \mathrm{~cm}^{2}$ ). Diagnostic cardiac catheterization and angiography revealed moderate tricuspid stenosis (valve area: $0.6 \mathrm{~cm}^{2}$ by Gorlin's method) with a diastolic pressure gradient of $11.1 \mathrm{mmHg}$ and second degree tricuspid regurgitation. No calcification was noted at the valve leaflets. However, the pressure gradient across the tricuspid valve increased $2 \mathrm{mmHg}$ after rapid loading of a $200 \mathrm{ml}$ saline solution, suggesting that she would experience difficulty coping with the additional volume load of pregnancy. Since she did not accept open surgical valve replacement, dilatation of the bioprosthesis by percutaneous balloon valvuloplasty was attempted.

She was premedicated with oral diazepam $(5 \mathrm{mg})$ and calcium pentobarbital (50 mg). Heparin, 5,000 units, was administered intravenously. Right-sided cardiac catheterization using a No. 7F flow directed Swan-Ganz catheter inserted percutaneously through the right femoral vein revealed a mean right atrial pressure of $9 \mathrm{mmHg}$ and a right ventricular pressure of $23 /-1 \mathrm{mmHg}$. The mean diastolic pressure gradient across the prosthetic tricuspid valve was 11 mmHg. Cardiac output measured by thermodilution was $4.3 \mathrm{l} / \mathrm{min}$ (cardiac index: $3.0 \mathrm{l} / \mathrm{min} / \mathrm{m}^{2}$ ). Before valvuloplasty, it was noted that the Swan-Ganz catheter (balloon diameter: $0.7 \mathrm{~cm}$ ) could not pass the tricuspid position when the balloon was inflated.

A No. 12F 20-mm-diameter specially manufactured Inoue balloon catheter (Toray) with a barrel-like shape at full inflation and $12 \mathrm{~F}$ size in diameter at deflation was inserted through a No. $14 \mathrm{~F}$ sheath introducer from the right femoral vein. The catheter passed the tricuspid valve easily. The balloon was inflated to $20 \mathrm{~mm}$ in diameter a total of 3 times as described previously. ${ }^{3)}$ This was followed by a No. 12F 22-mm-diameter catheter also inflated a total of 3 times. The diameters of the balloons were determined based on the diameter of the Hancock valve stents. The balloon was carefully and gradually inflated, and the mean inflation time was 30 seconds under monitoring. Each inflation was accompanied by transient tachycardia and hypotension. After serial inflations, the balloon could be fully inflated (Figure). The hemodynamic findings before and immediately after valvuloplasty are summarized in the Table. Mean tricuspid pressure gradient decreased from $11.1 \mathrm{mmHg}$ to $7.5 \mathrm{mmHg}$. The calculated tricuspid valve area was mildly increased by $0.9 \mathrm{~cm}^{2}$ using Gorlin's method. The Swan- 


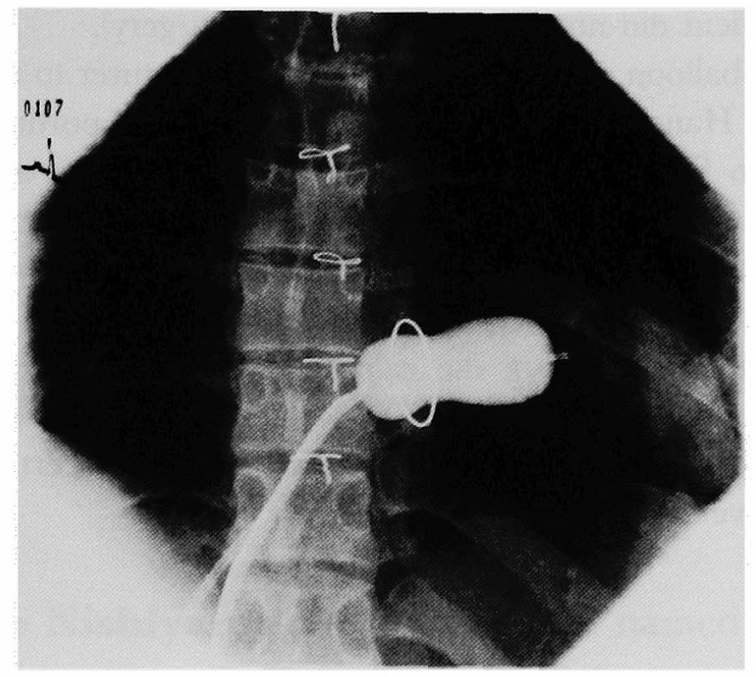

Figure. The dilatation balloon positioned across the tricuspid valve. The last inflation of the balloon with contrast media is shown. The waist of the balloon is visible, but it does not mean an unsuccessful valvuloplasty. Because the waist of the balloon was modified to fit the stent of the Hancock valve, it remained even when the balloon was fully inflated.

Table. Cardiac Catheterization Data

\begin{tabular}{lcc}
\hline & Pre & Post \\
\hline Pressure (mmHg) & & \\
Right atrium (RA) & $(9)$ & $(5)$ \\
Right ventricle (RV) & $23 /-1$ & $27 / 2$ \\
Pulmonary artery & $13 / 2(4)$ & $17 / 4(8)$ \\
Pulmonary artery wedge & $(1)$ & $(2)$ \\
Pressure gradient $(\mathrm{RA}-\mathrm{RV})(\mathrm{mmHg})$ & 11.1 & 7.5 \\
Cardiac output $(l /$ min) by thermodilution method & 4.3 & 4.6 \\
Tricuspid valve area $\left(\mathrm{cm}^{2}\right)$ by Gorlin's method & 0.6 & 0.9 \\
Tricuspid regurgitation by right ventriculography & $\mathrm{II}^{\circ}$ & $\mathrm{II}^{\circ}$ \\
\hline
\end{tabular}

Values in parentheses indicate mean pressure.

Ganz catheter with the balloon inflated could now easily pass the tricuspid valve. After the hemodynamic values were measured, right ventriculography was performed. Second degree tricuspid regurgitation was noted which was slightly increased from before valvuloplasty. Compared to percutaneous transluminal balloon valvuloplasty for native valvular stenosis, the tricuspid stenosis in this case was not improved sufficiently, and it was unclear whether this improvement of the tricuspid stenosis was adequate for pregnancy and delivery. However, this case suggests that percutaneous balloon valvuloplasty is an alternative to open surgical valve replacement in certain patients with bioprosthetic valve stenosis (in 
this case, the patient did not agree to open heart surgery).

The Inoue balloon was modified by the manufacturer to take into account the shape of the Hancock valve. The central constricted portion of the balloon was clongated to fit the stents of the Hancock valve. The advantage of this balloon was that the valvuloplasty could be performed without a guidewire. Although there was some residual tricuspid stenosis, both the mean right atrial pressure and the mean diastolic pressure gradient between the right atrium and right ventricle decreased. Also, the calculated tricuspid valve area increased. There were no major complications. We conclude that percutaneous balloon valvuloplasty offers a reasonable alternative to surgery in certain patients with bioprosthetic valve stenosis.

\section{ACKNOWLedgMents}

We thank Dr. Kanji Inoue for his valuable advice regarding balloon construction and also Toray for kindly providing the balloons.

\section{References}

1. Kan JS, White RI, Jr, Mitchell SE, Gardner TJ: Percutaneous balloon valvuloplasty; a new method for treating congenital pulmonary valve stenosis. N Engl J Med 307: 540, 1982

2. Feit F, Stecy PJ, Nachamie MS: Percutaneous balloon valvuloplasty for stenosis of a porcine bioprosthesis in the tricuspid valve position. Am J Cardiol 58: 363, 1986

3. Inoue $\mathbf{K}$, Owaki T, Nakamura T, Kitamura F, Miyamoto $\mathrm{N}$ : Clinical application of transvenous mitral commissurotomy by a new balloon catheter. J Thorac Cardiovasc Surg 87: 394, 1984 